\title{
Temperature-Dependent Viscosity of Organic Materials Characterized by Atomic Force Microscope
}

\author{
Yiming Qin ${ }^{1, *} \neq$, Jianhuai Ye ${ }^{1,+}$, Paul Ohno ${ }^{1}$, Theodora Nah ${ }^{2}$ (D) and Scot T. Martin ${ }^{1,3}$ (D) \\ 1 School of Engineering and Applied Sciences, Harvard University, Cambridge, MA 02138, USA; \\ yejh@sustech.edu.cn (J.Y.); pohno@fas.harvard.edu (P.O.); scot_martin@harvard.edu (S.T.M.) \\ 2 School of Energy and Environment, City University of Hong Kong, Hong Kong 518057, China; \\ theodora.nah@cityu.edu.hk \\ 3 Department of Earth and Planetary Sciences, Harvard University, Cambridge, MA 02138, USA \\ * Correspondence: yiminq2@uci.edu \\ + Now at: School of Environmental Science and Engineering, Southern University of Science and Technology, \\ Shenzhen 518055, China. \\ $\ddagger$ Now at: Department of Chemistry, University of California Irvine, Irvine, CA 92697, USA.
}

Citation: Qin, Y.; Ye, J.; Ohno, P.; Nah, T.; T. Martin, S. TemperatureDependent Viscosity of Organic Materials Characterized by Atomic Force Microscope. Atmosphere 2021, 12, 1476. https://doi.org/10.3390/ atmos12111476

Academic Editor: Tomasz Gierczak

Received: 29 September 2021

Accepted: 5 November 2021

Published: 8 November 2021

Publisher's Note: MDPI stays neutral with regard to jurisdictional claims in published maps and institutional affiliations.

Copyright: (c) 2021 by the authors. Licensee MDPI, Basel, Switzerland. This article is an open access article distributed under the terms and conditions of the Creative Commons Attribution (CC BY) license (https:// creativecommons.org/licenses/by/ $4.0 /)$.

\begin{abstract}
The viscosity of atmospheric aerosol particles determines the equilibrium timescale at which a molecule diffuses into and out of particles, influencing processes such as gas-particle partitioning, light scattering, and cloud formation that can affect air quality and climate. This particle viscosity is sensitive to environmental conditions such as relative humidity and temperature. Current experimental techniques mainly characterize aerosol viscosity at room temperature. The influence of temperature on the viscosity of organic aerosol remains underexplored. Herein, the viscosity of atmospherically relevant organic materials was examined at a range of temperatures from $15{ }^{\circ} \mathrm{C}$ to $95^{\circ} \mathrm{C}$ using an atomic force microscope (AFM) equipped with a temperature-controlled sample module. Dioctyl phthalate and sucrose were selected for investigation. Dioctyl phthalate served as the proxy for atmospherically relevant primary organic materials while sucrose served as the proxy for secondary organic materials. The resonant frequency responses of the AFM cantilever within dioctyl phthalate and sucrose were recorded. The link between the resonant frequency and material viscosity was established via a hydrodynamic function. Results obtained from this study were consistent with previously reported viscosities, thus demonstrating the critical capability of AFM in temperature-dependent viscosity measurements.
\end{abstract}

Keywords: viscosity; temperature-dependent; atomic force microscope

\section{Introduction}

Atmospheric particles play a crucial role in environmental processes. They affect the radiative balance of the Earth by scattering and absorbing solar and terrestrial radiation, influencing cloud formation and cloud lifetime [1,2]. The magnitudes of these environmental effects depend on the physicochemical properties of particles, such as their size and chemical composition. Particle viscosity determines the equilibrium timescale of a molecule that partitions between the gas and particle phases [3,4]. The high viscosity of the particle can impose kinetic limitations to mass transfer within the particle phase, thereby affecting the evolution of the size, chemical composition of the particle, and the gas-particle partitioning of atmospheric species. Environmental factors, such as relative humidity and temperature, can influence the viscosity of the particle [4,5]. The effect of relative humidity on viscosity has been the focus of extensive studies over the past few decades [6-10]. In higher relative humidity conditions, the higher water content in the particle phase decreases the viscosity of the particle. At lower relative humidity conditions, water evaporates, thereby increasing the viscosity of the particle [3]. In theory, the viscosity of a material is expected to increase with temperature, as demonstrated by the 
Arrhenius equation and Vogel-Fulcher-Tammann equation, but there are few experimental methods available to measure the viscosity at different temperatures [11]. As a result, our current understanding of how temperature affects particle viscosity is limited, and temperature-dependent viscosity measurements are in urgent need.

Traditional methods for measuring the viscosity of a material involve the use of a rheometer or a viscometer. However, these approaches require a large sample mass, which is often impractical in atmospheric chemistry due to the small amount of particulate material that is collected from the atmosphere in a typical collection period [11,12]. Over the last two decades, new techniques, such as particle rebound, shape relaxation, bead mobility, poke flow, and aerosol optical tweezers, have been established to measure the viscosity of organic aerosol material [6-9]. However, with few exceptions [13,14], due to experimental challenges, these previous studies mostly measure particle viscosity at room temperature.

The microcantilever vibrational of atomic force microscopy (AFM) is sensitive to the viscosity of the materials surrounding it $[15,16]$. The thermal vibrations can be approximated as a simple harmonic oscillator when the cantilever is immersed in vacuum and a dissipative harmonic oscillator when it is in a viscous medium. The quantitative relationship between viscosity and the resonant frequency response can be obtained using a hydrodynamic model, which was initially developed to calibrate the spring constant of the cantilever in viscous materials [17]. The AFM technique has been applied to measure the viscosity of sucrose and several organic materials at room temperature [18,19]. In recent years, there are commercially available AFM sampling stages that enable temperature control across a wide range. For example, the Cypher ES environmental sample stage equipped with a temperature control module is widely used for AFM measurements, which offers a temperature-controlled measurement from $0{ }^{\circ} \mathrm{C}$ to $120^{\circ} \mathrm{C}$. Coupling a temperature control module with the AFM viscosity measurement has not been previously studied to the best of our knowledge.

The study herein investigated the viscosities of atmospherically relevant organic materials at a range of temperatures from $15^{\circ} \mathrm{C}$ to $95^{\circ} \mathrm{C}$ using a Cypher AFM equipped with the ES sample stage. Dioctyl phthalate (DOP) and sucrose were chosen as prototypical atmospherically relevant organic materials. With high $\mathrm{H}: \mathrm{C}$ and low $\mathrm{O}: \mathrm{C}$ ratios, DOP often serves as a proxy for hydrophobic primary organic materials in the atmosphere [20], which can be generated from vinyl flooring, shower curtains, and car interior trim in indoor environments and tire wear in outdoor environments [21]. In contrast, sucrose has a high $\mathrm{O}: \mathrm{C}$ ratio and is water soluble. It is commonly found in atmospheric particles, and it is usually used to surrogate highly oxidized water-soluble secondary organic materials in the atmosphere $[13,22]$.

\section{Materials and Methods}

Sucrose solution $(10 \% w / w)$ was prepared by dissolving sucrose $(\geq 99.5 \%$, SigmaAldrich, St. Louis, MO, USA) in high-performance liquid chromatography-grade water. The solution was sonicated for $15 \mathrm{~min}$ to ensure complete dissolution. DOP ( $\geq 99.5 \%$, Sigma-Aldrich, St. Louis, MO, USA) was used directly without pretreatment. Sucrose solution and DOP were deposited on a mica substrate (RED PELLA, INC., Altadena, CA, USA). Mica is commonly used in AFM measurements because of its chemical and thermal stability [23]. The volume of the materials used was approximately $50 \mu \mathrm{L}$. Cantilevers with spring constant in the range of $0.01 \mathrm{~N} \mathrm{~m}^{-1}$ to $100 \mathrm{~N} \mathrm{~m}^{-1}$ are commercially available. Typically, a cantilever with a low spring constant is more sensitive to materials with low viscosity, while a cantilever with a high spring constant is more sensitive to high viscosity materials [18]. In the study herein, a cantilever with a spring constant of $2 \mathrm{~N} \mathrm{~m}^{-1}$ (AC240TSA-R3, Asylum Research Probes, Asylum Research, Santa Barbara, CA, USA) was used for sucrose measurements. A cantilever with a spring constant of $26 \mathrm{~N} \mathrm{~m}^{-1}$ (AC160TS-R3, Asylum Research Probes, Asylum Research, Santa Barbara, CA, USA) was used for DOP measurements. 
A laser beam was focused on the top surface of the probe cantilever during the measurement, and a photodiode array was used to detect the reflected laser beam. The differential signal of the photodiode monitors the thermal oscillation of the cantilever. The thermal oscillations in the air and the target materials were recorded. The thermal vibrations of a cantilever can be approximated as a harmonic oscillator. In this approximation, the resonant frequency of the cantilever oscillation is proportional to the square root of the spring constant of the cantilever over the effective mass. The spring constant $(\mathrm{k})$ is a mechanical property of the cantilever, and it describes how stiff a cantilever is and how much it can be stretched or compressed. When the cantilever is immersed in the organic material, the oscillations of the cantilever are damped due to the added drag on the cantilever. The resulting increase in effective mass shifts the resonant frequency to a lower value, relative to its resonant frequency in air or vacuum. According to hydrodynamic modeling, the resonant frequency of the cantilever is a function of the density and viscosity of the surrounding materials [17]. Explicit analytical formulas of the model can be found in the literature [17]. In brief, the connection between cantilever resonant frequency and material viscosity can be linked through Equations (1)-(7) [17,24]:

$$
k=0.1906 \rho_{f} W^{2} L Q_{f} \Gamma_{i}\left(\omega_{f}\right) \omega_{f}^{2}
$$

where $\rho_{f}$ is the density of the measuring materials; $W$ and $L$ are the width and length of the cantilever, respectively; $Q_{f}$ is the resonant quality factor of the measuring materials; $\omega_{f}$ is the cantilever resonant frequency; $\Gamma_{i}\left(\omega_{f}\right)$ is the imaginary component of a hydrodynamic function $\Gamma_{\omega}$, which is a function of Reynolds number that connects the viscosity of the materials to the response that can be calculated as follows [17]:

$$
\begin{gathered}
\Gamma\left(\omega_{f}\right)=\Omega\left(\omega_{f}\right)\left[1+\frac{4 i K_{1}((-i) \sqrt{i \operatorname{Re}})}{\sqrt{i \operatorname{Re}} K_{0}((-i) \sqrt{i R e})}\right] \\
\Omega\left(\omega_{f}\right)=\Omega_{r}\left(\omega_{f}\right)+\mathrm{i} \Omega_{i}\left(\omega_{f}\right)
\end{gathered}
$$

where $\Omega_{r}\left(\omega_{f}\right)$ and $\Omega_{i}\left(\omega_{f}\right)$ is the real and imaginary parts of the $\Omega\left(\omega_{f}\right)$, respectively [17]. The functions $K_{0}$ and $K_{1}$ are the modified Bessel function of the third kind [25].

$$
\begin{gathered}
\Omega_{r}\left(\omega_{f}\right)=\frac{0.91324-0.48274 \tau+0.46842 \tau^{2}-0.12886 \tau^{3}+0.044055 \tau^{4}-0.0035117 \tau^{5}+0.00069085 \tau^{6}}{1-0.56964 \tau+0.48690 \tau^{2}-0.13444 \tau^{3}+0.045155 \tau^{4}-0.0035862 \tau^{5}+0.00069085 \tau^{6}} \\
\Omega_{i}\left(\omega_{f}\right)=\frac{-0.024134-0.029256 \tau+0.016294 \tau^{2}-0.00010961 \tau^{3}+0.000064577 \tau^{4}-0.000044510 \tau^{5}}{1-0.59702 \tau+0.55182 \tau^{2}-0.18357 \tau^{3}+0.079156 \tau^{4}-0.014369 \tau^{5}+0.0028361 \tau^{6}} \\
\tau=\log _{10}(R e)
\end{gathered}
$$

The Reynolds number of the fluid is a dimensionless number describing the ratio of inertial forces to viscous forces in a flowing fluid, and is as follows:

$$
\eta=\frac{\rho_{f} \omega_{f} W^{2}}{4 R e}
$$

where $\eta$ is the viscosity of the measuring material.

The schematics and procedures used to determine the viscosity of the materials at different temperatures using the AFM are shown in Figure 1. The model, which includes Equations (1)-(7), connects the experimentally determined cantilever resonant frequency and the viscosity to the spring constant of the cantilever. 
a.

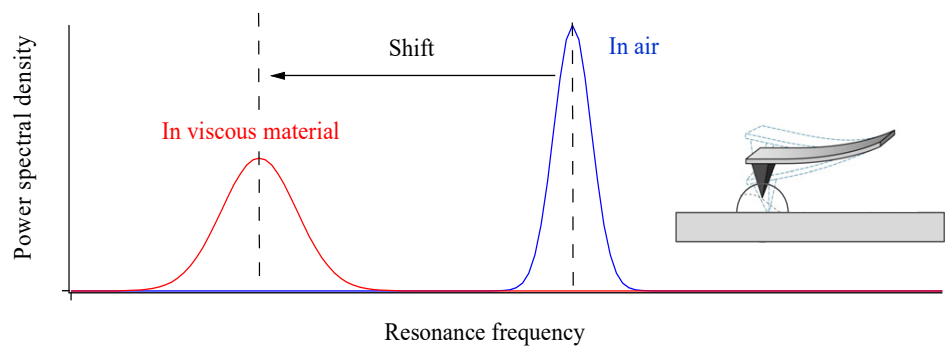

b.

\begin{tabular}{|l|l|}
\hline 1) Resonance frequency of AFM \\
cantilever in the air
\end{tabular}

Figure 1. Schematic illustrating the technique of using AFM cantilever combined with hydrodynamic model in measuring the viscosity of organic materials at different temperatures. (a) Schematic illustrating the shift in resonance frequencies of AMF cantilever in air and in viscous materials; (b) Procedures in obtaining the viscosity of organic materials.

The cantilever's spring constant was determined by measuring the resonant frequency of the cantilever in the air, which has a known viscosity and density $(18.6 \mu \mathrm{Pa} \mathrm{s}$ and $1.184 \mathrm{~kg} \mathrm{~m}^{-3}$ at $25^{\circ} \mathrm{C}$ ) and calculated using the hydrodynamic model. For the same cantilever, the spring constant remains the same regardless of the medium surrounding it. The resonant frequency, including its mode and quality factor, depends on the viscosity and the density of the materials. The mode of the resonant frequency and quality factor were obtained by Gaussian fitting of the power spectral density data. For materials with known density, the resonant frequency is a function of viscosity. For materials with little variation in density at different temperatures, the resonant frequency can be used to calculate the viscosity of the material without specifying the density at each temperature. In the study herein, literature-reported densities of $10 \% \mathrm{w} / \mathrm{w}$ sucrose and DOP at different temperatures are summarized in Table S1. Therefore, the viscosity of the $10 \% w / w$ sucrose and DOP can be estimated using the hydrodynamic model with Equations (1)-(7).

\section{Results}

Figure 2 shows the power spectral density of the AFM cantilever (AC240TSA-R3) oscillation in air and $10 \% \mathrm{w} / \mathrm{w}$ sucrose solution at $25^{\circ} \mathrm{C}$. The resonant frequency was $79.5 \mathrm{kHz}$ when the cantilever was oscillating in the air at $25^{\circ} \mathrm{C}$. It shifted to $30.1 \mathrm{kHz}$ when the cantilever oscillated in the sucrose solution at the same temperature. This shift in the resonant frequency can be attributed to the viscous damping of the cantilever oscillation. It is noted that an increase in temperature may cause thermal expansion of the cantilever, which may affect its natural frequency. However, this shift due to thermal expansion is expected to be much smaller than the frequency shift caused by the change in viscosity of the surrounding materials.

To explore the feasibility of the temperature-dependent viscosity measurement using the AFM, the resonance frequency of the cantilever when it was immersed in sucrose solution and dioctyl phthalate was measured as a function of temperature. The resonant frequency measurements were conducted until the temperature of the organic materials was stable $\left( \pm 0.1{ }^{\circ} \mathrm{C}\right.$ uncertainty). As shown in Figure 3, both the sucrose solution (in pink) and the DOP (in green), resonant frequencies increased systematically as temperature increased. The higher frequency response at more elevated temperatures represented the lower resistance force of the organic materials on the cantilever oscillations. It should be noted that the frequency response of the sucrose solution and the DOP cannot be directly compared in this study because the cantilevers used were different. 


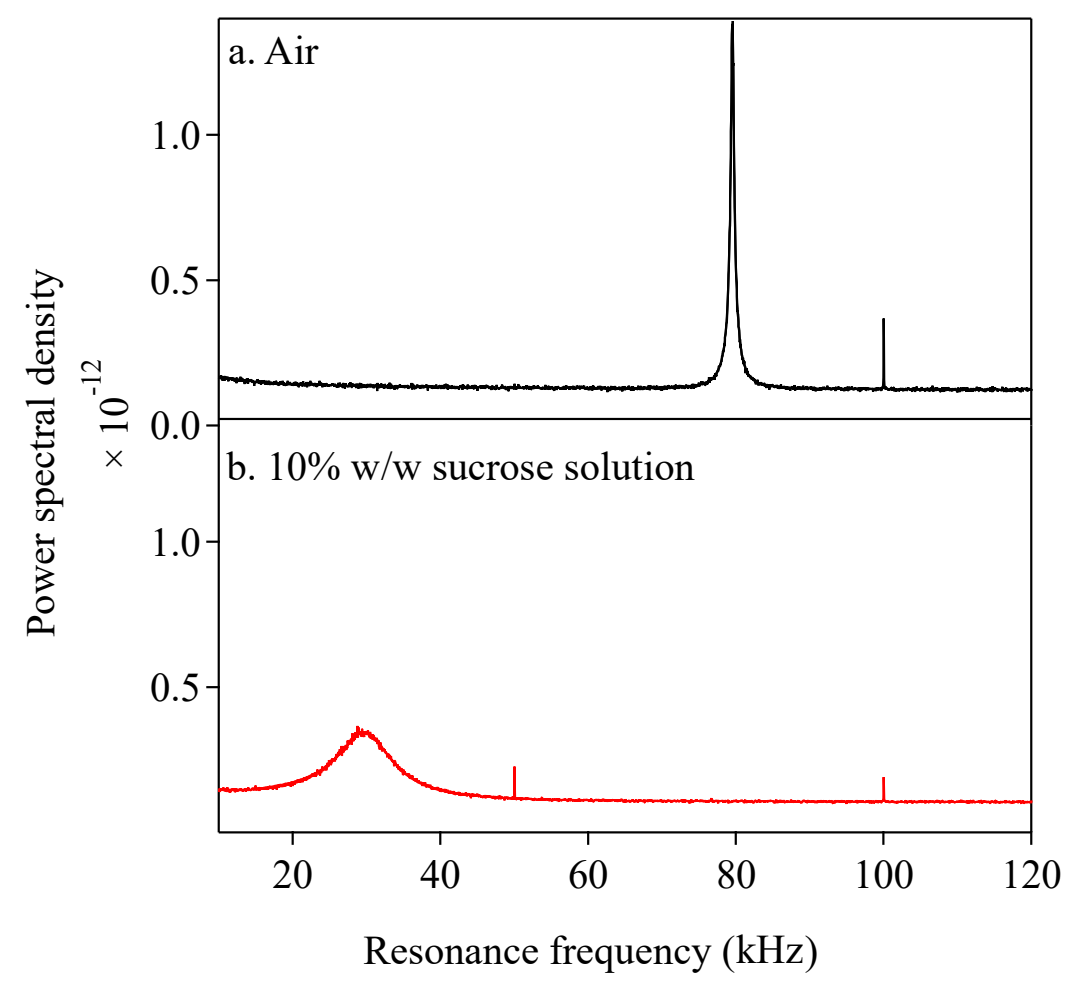

Figure 2. Power spectra density function of AFM cantilever oscillation. (a) in air at $25^{\circ} \mathrm{C}$; (b) in $10 \%$ $w / w$ sucrose at $25^{\circ} \mathrm{C}$. (Cantilever AC240TSA-R3).

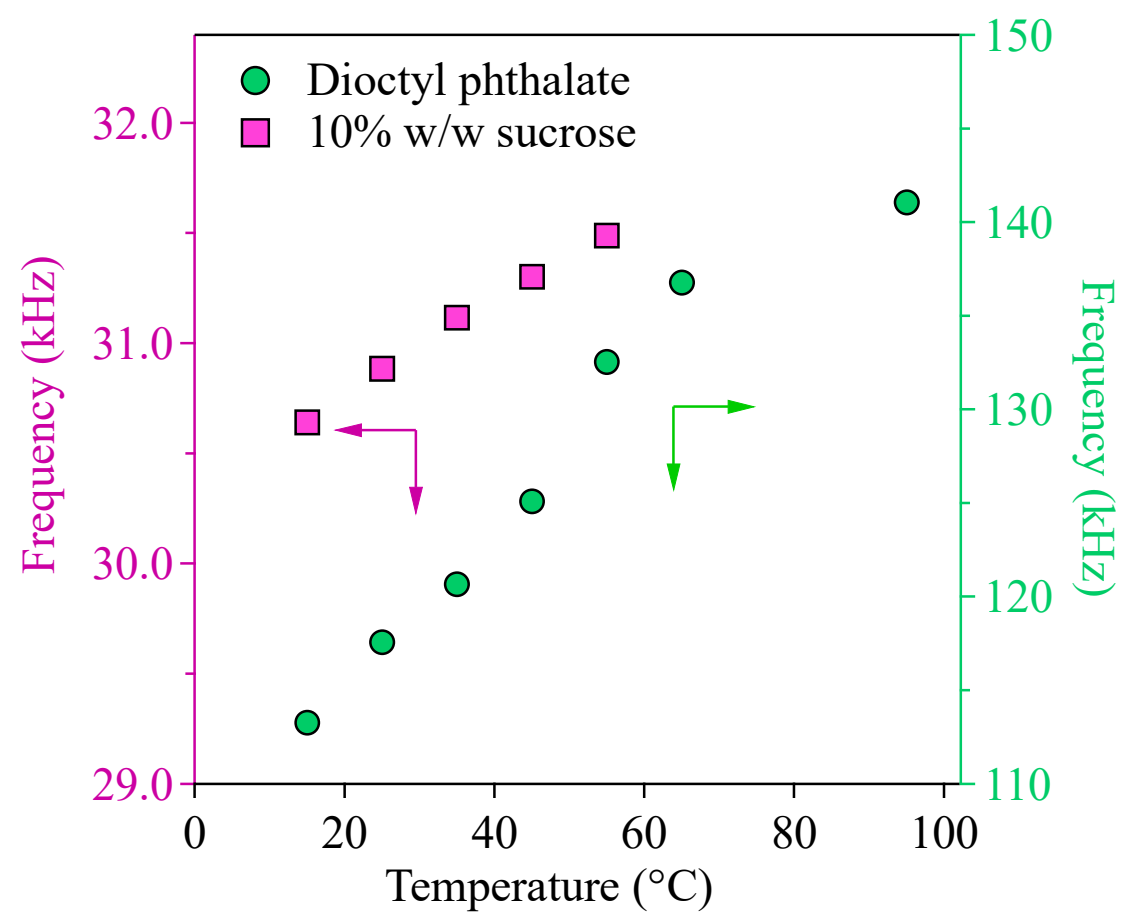

Figure 3. Resonance frequencies of AMF cantilever in the $10 \% w / w$ sucrose and dioctyl phthalate at temperatures from $15{ }^{\circ} \mathrm{C}$ to $90{ }^{\circ} \mathrm{C}$. (Cantilever AC240TSA-R3 was used for $10 \% w / w$ sucrose; cantilever AC160TS-R3 was used for the dioctyl phthalate). The closed symbols are the average resonance frequencies of three measurements. The shaded areas are the standard deviation of the three measurements. 
Figure 4 shows the frequency response of the sucrose solution and the DOP against the viscosity retrieved from the hydrodynamic model. The temperatures at which the frequency responses were taken are color-coded for each data point. As expected, the resonant frequency of the cantilever was shifted toward lower frequencies in the more viscous solutions.

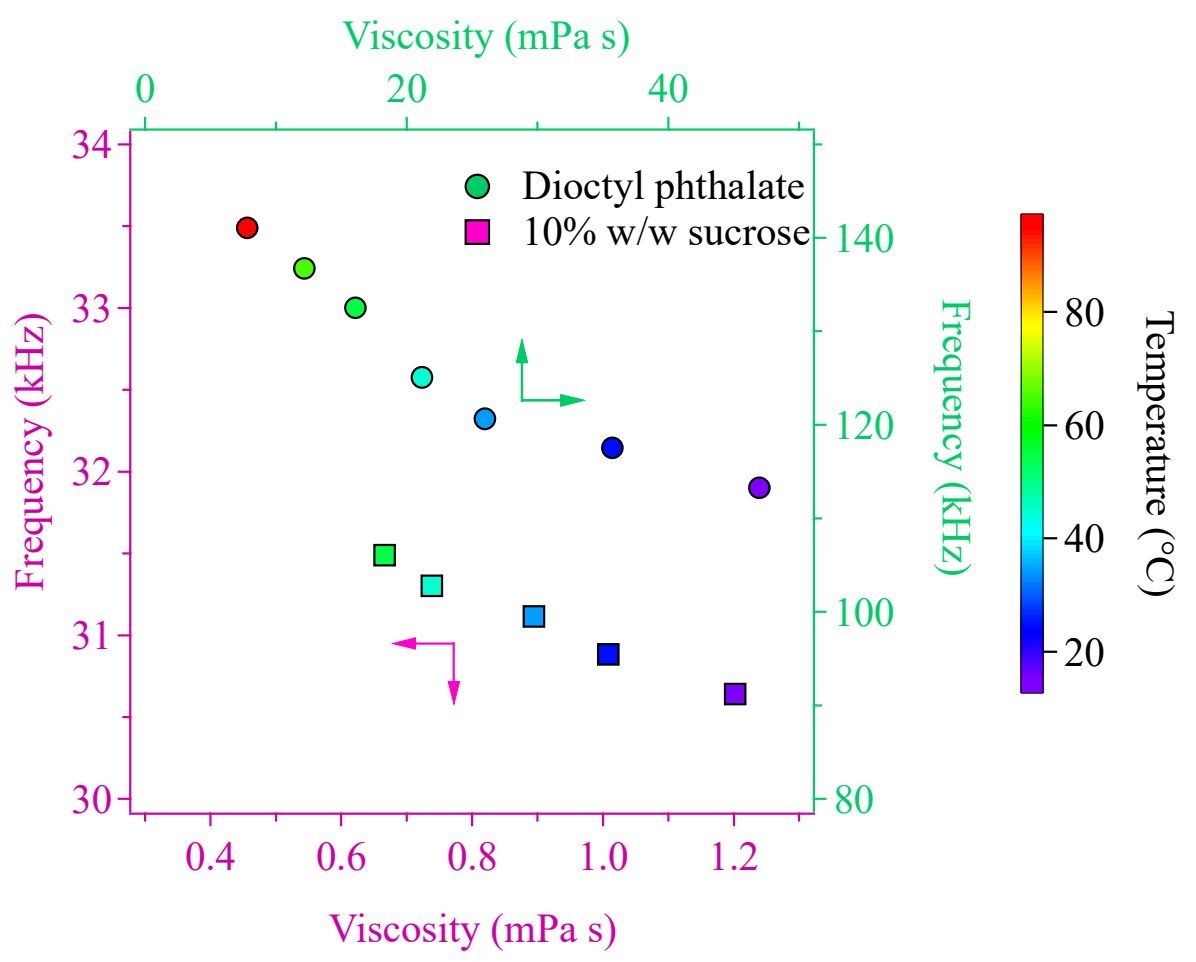

Figure 4. Resonant frequencies of the $10 \% w / w$ sucrose and dioctyl phthalate as a function of the viscosity retrieved from the hydrodynamic model. The closed symbols are the average resonance frequencies of three measurements. The shaded area is the standard deviation of the three measurements.

The temperature-dependent viscosities of $10 \% w / w$ sucrose and the DOP are shown in Figure 5. The closed symbols are the viscosity values obtained from the current study. The open symbols are the viscosity values reported in the literature. In the current study, the viscosity decreased as temperature increased for the $10 \% w / w$ sucrose and the DOP. For the $10 \% w / w$ sucrose, the viscosity decreased to $55 \%$ (from 1.2 to $0.66 \mathrm{mPa}$ ) as the temperature increased from $15{ }^{\circ} \mathrm{C}$ to $55^{\circ} \mathrm{C}$. For the DOP, the viscosity decreased to $35 \%$ (from 88.80 to $30.90 \mathrm{mPa}$ s) as the temperature increased from $15{ }^{\circ} \mathrm{C}$ to $55^{\circ} \mathrm{C}$, and further down to $17 \%$ ( $15 \mathrm{mPa}$ s) when the temperature reached $95^{\circ} \mathrm{C}$. The viscosity values reported from this study agree with those reported in the literature (Figure 5). For example, in the study by Telis et al. [26], the viscosities of $10 \% w / w$ sucrose solution at temperatures of $15^{\circ} \mathrm{C}$, $25^{\circ} \mathrm{C}, 35^{\circ} \mathrm{C}, 45^{\circ} \mathrm{C}$, and $55^{\circ} \mathrm{C}$ were $1.41,1.13,0.89,0.74$, and $0.57 \mathrm{mPa}$ s from the rheometer (open squares in Figure 5), while the values were 1.41, 1.13, $0.92 \mathrm{mPa}$ s at temperatures of $15{ }^{\circ} \mathrm{C}, 25^{\circ} \mathrm{C}, 35^{\circ} \mathrm{C}$ from the viscometer (open triangles in Figure 5). Rheometer and viscometer are traditional ways to measure the viscosity of the materials but require a large amount of the materials. Those values line within $20 \%$ difference compared to the current study. In addition, Lorenzi et al. [27] measured the viscosity of the DOP at a range of temperatures from $20{ }^{\circ} \mathrm{C}$ to $122{ }^{\circ} \mathrm{C}$. In that study, the viscosity of the DOP ranged from 55.76 to $5.12 \mathrm{mPa} s$ when the temperature changed from $20^{\circ} \mathrm{C}$ to $122{ }^{\circ} \mathrm{C}$ (Figure 5, open circles). These viscosity values were in general consistent with the method herein. The closer agreement with literature values for sucrose than for DOP can be attributed to many factors such as experimental uncertainty and differences in sample volume used among studies. A higher aspect ratio of the cantilever used for sucrose than for DOP may also contribute to the observation results. In addition, the aspect ratio of the cantilever 
can be different in air and in liquid under the same environmental conditions, although the change is expected to be minimal. By applying the same spring constant measured in air to the measurement in liquid may lead to uncertainties. A sensitivity test using cantilevers with different aspect ratios and in different tested media can be conducted in the future. In conclusion, our results were validated by previously reported viscosities, thus demonstrating the critical capability of temperature-dependent viscosity measurement using the AFM.

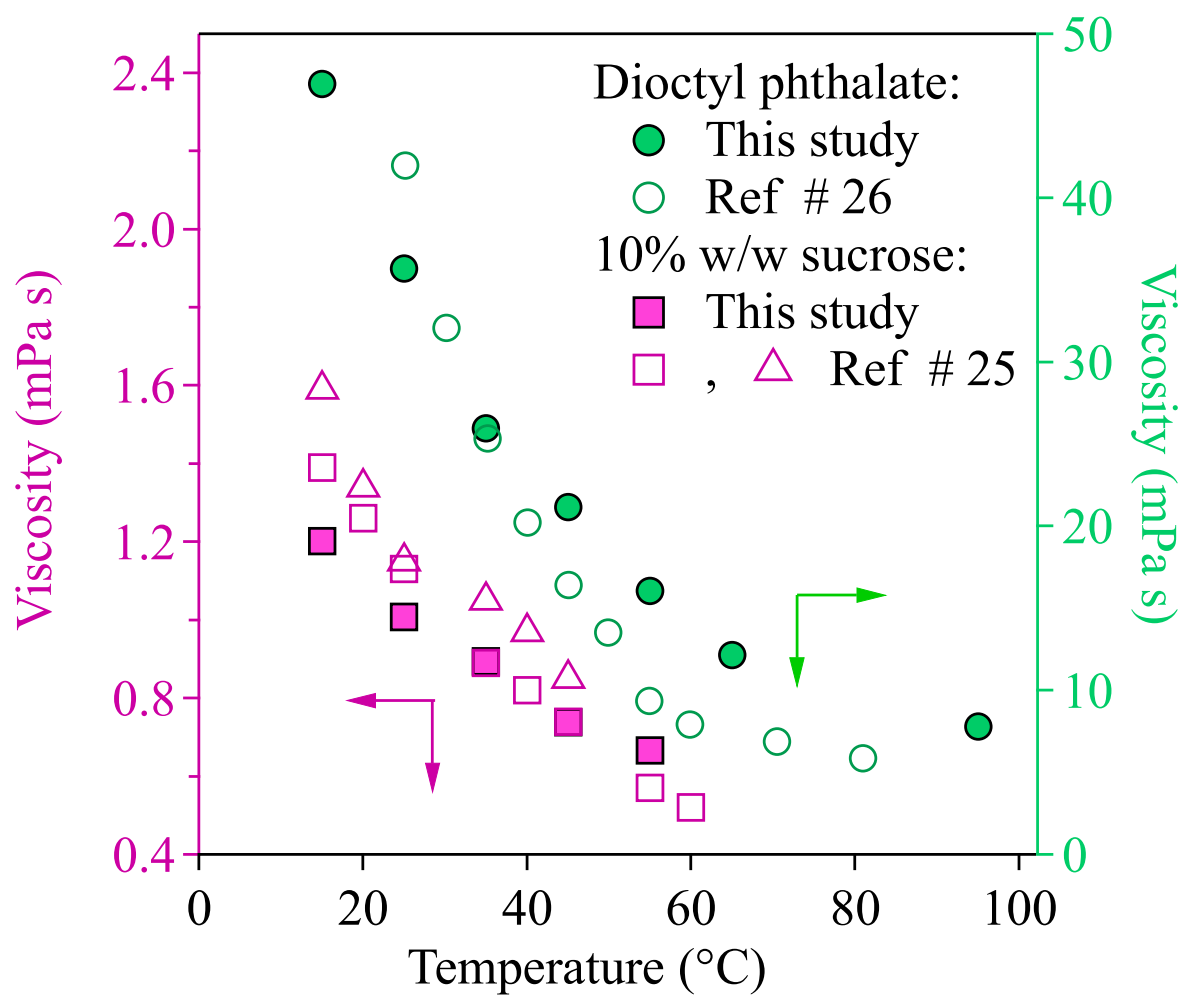

Figure 5. Comparison among the temperature-dependent viscosity of this study and those of other reports in the literature for the $10 \% w / w$ sucrose [26] and dioctyl phthalate [27].

As the temperature increased, kinetic motion increased, which enhanced the breaking of intermolecular bonds between adjacent layers, thus reducing the viscosity [28]. The decreases in the viscosity as temperature increases follows the Arrhenius equation [29,30]:

$$
\ln (\eta)=\ln \left(A_{0}\right)+\frac{E_{a}}{R}\left(\frac{1}{T}\right)
$$

where $R, E_{a}$, and $A_{0}$ are the gas constant, the Arrhenius activation energy, and the preexponential factor of the Arrhenius equation, respectively. Figure 6 shows the results of the fits to the experimental data using the Arrhenius equation. The Arrhenius equation fitted the temperature-dependent viscosity with an $\mathrm{R}^{2}$ of 0.99 (shown in Figure 6). The $E_{a}$ values for viscosity determined from the Arrhenius fits were $11.73 \mathrm{~kJ} \mathrm{~mol}^{-1}$ and $20.26 \mathrm{~kJ} \mathrm{~mol}^{-1}$ for the $10 \% w / w$ sucrose and $100 \% w / w$ DOP, respectively. Higher $E_{a}$ values were obtained for DOP compared to the sucrose solution. This indicated that the change in temperature led to larger changes in viscosity for DOP compared to the sucrose solution. 


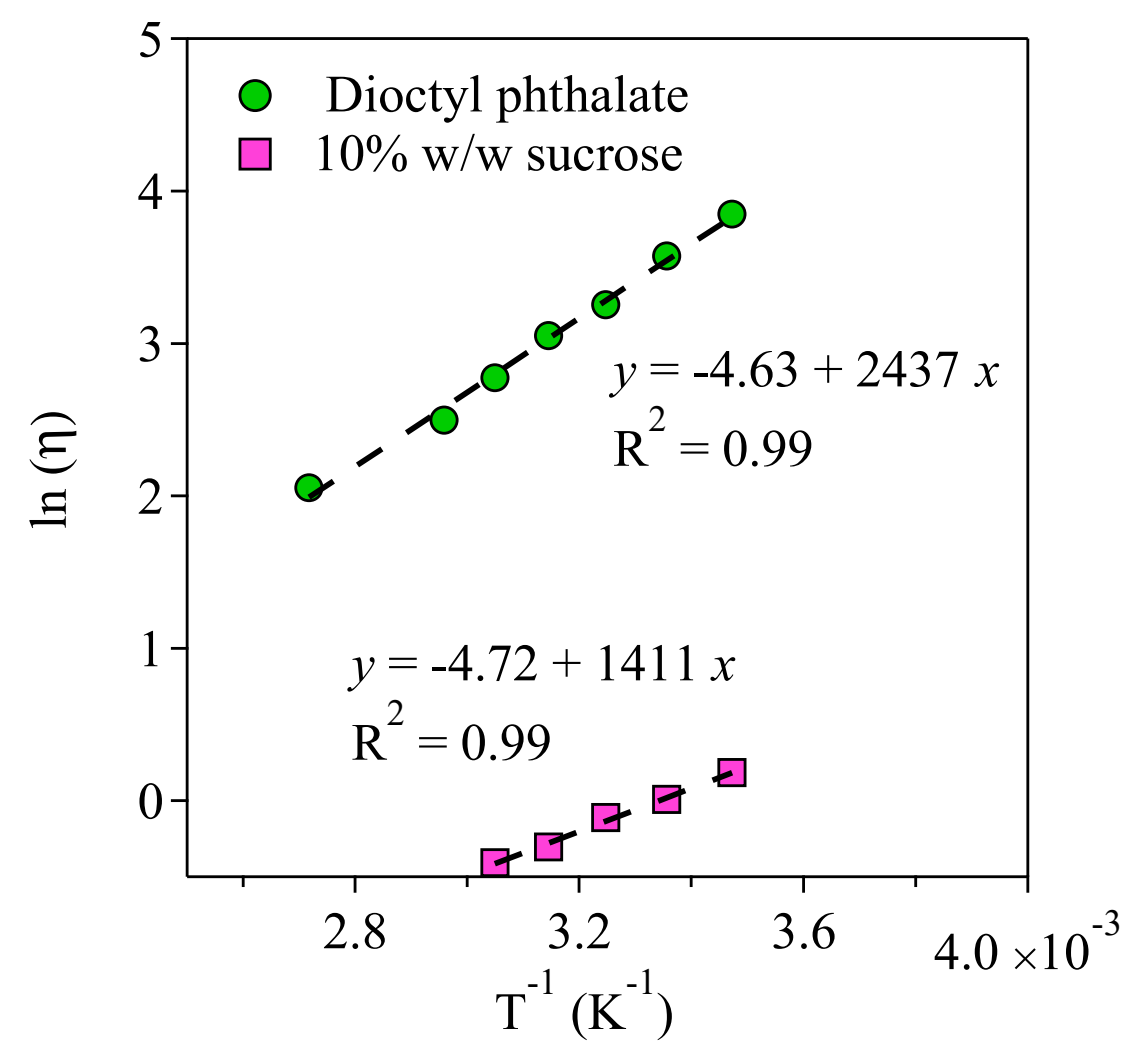

Figure 6. Natural logarithm of the viscosities of the $10 \% \mathrm{w} / \mathrm{w}$ sucrose and dioctyl phthalate as a function of inverse temperature.

\section{Conclusions}

Understanding the viscosities of organic aerosol particles is crucial for predicting the partitioning of organic compounds between the gas and particle phases, heterogeneous reaction rates of pollutants, and the efficiency of ice nucleation. The influence of temperature on the viscosity of an organic aerosol particle currently remains underexplored. In this work, the viscosities of two organic aerosol surrogates, sucrose, and DOP, at temperatures from $15^{\circ} \mathrm{C}$ to $95^{\circ} \mathrm{C}$ were measured using a Cypher atomic force microscope (AFM) equipped with a Cypher ES temperature-controlled sample stage. The results were validated by previously reported viscosities in the literature. The current method of combining AFM with a temperature-controlled sample stage is highly versatile. It can take viscosity measurements of both hydrophobic organic matter (such as DOP) and water-soluble organic matter (such as sucrose), which are commonly found in atmospheric aerosols. The AFM combined with the temperature-controlled sample stage offers promise towards improving our understanding of the temperature-dependent viscosity of different types of aerosol systems. This work serves as a proof of concept in measuring the temperaturedependent viscosity of organic materials using AFM, although the viscosity measured in the current study lies in the upper limits of that of the organic aerosol. Systematic viscosity measurements of different organic materials at lower temperatures can be explored in the future. In addition, AFM is a useful tool for characterizing various processes at nanoscales and has been used successfully to probe the phase state of individual aerosol particles [31-34], another future application of the AFM technique can be examining the size-dependent viscosity of aerosol particles, and comparing the difference of the viscosity of the same materials in bulk solution, droplets, and nanoparticles.

Supplementary Materials: The following are available online at https:/ /www.mdpi.com/article/10 $.3390 / \mathrm{atmos} 12111476 / \mathrm{s} 1$, Table S1: the density of the $10 \% w / w$ sucrose and DOP at the temperature range from $10{ }^{\circ} \mathrm{C}$ to $84^{\circ} \mathrm{C}$. 
Author Contributions: Conceptualization, Y.Q.; methodology, Y.Q.; writing-original draft preparation, Y.Q.; writing - review and editing, J.Y., P.O., T.N. and S.T.M. All authors have read and agreed to the published version of the manuscript.

Funding: This work was funded in part by the program in Environmental Chemical Sciences of the Division of Chemistry of the USA National Science Foundation (ECS-2003368).

Institutional Review Board Statement: Not applicable.

Informed Consent Statement: Not applicable.

Data Availability Statement: ASCII tab-delimited files of the resonant frequency responses of the AFM cantilever in the sucrose and dioctyl phthalate; the temperature-dependent viscosities of the sucrose and dioctyl phthalate are available at https:/ / doi.org/10.7910/DVN/MHKRJN (accessed on 7 November 2021).

Acknowledgments: This work was performed at the Harvard Center for Nanoscale Systems (CNS), a member of the NSF National Nanotechnology Infrastructure Network (NNIN). The authors thank Jason Tresback from the CNS for the technical support of the AFM measurement.

Conflicts of Interest: The authors declare no conflict of interest. The funders had no role in the design of the study; in the collection, analyses, or interpretation of data; in the writing of the manuscript, or in the decision to publish the results.

\section{References}

1. Jacobson, M.Z. Global direct radiative forcing due to multicomponent anthropogenic and natural aerosols. J. Geophys. Res. Space Phys. 2001, 106, 1551-1568. [CrossRef]

2. Winker, D.M.; Pelon, J.; Coakley, J.A.; Ackerman, S.; Charlson, R.J.; Colarco, P.R.; Flamant, P.; Fu, Q.; Hoff, R.M.; Kittaka, C.; et al. The CALIPSO Mission. Bull. Am. Meteorol. Soc. 2010, 91, 1211-1230. [CrossRef]

3. Liu, P.; Li, Y.; Wang, Y.; Gilles, M.K.; Zaveri, R.A.; Bertram, A.K.; Martin, S.T. Lability of secondary organic particulate matter. Proc. Natl. Acad. Sci. USA 2016, 113, 12643-12648. [CrossRef]

4. Koop, T.; Bookhold, J.; Shiraiwa, M.; Pöschl, U. Glass transition and phase state of organic compounds: Dependency on molecular properties and implications for secondary organic aerosols in the atmosphere. Phys. Chem. Chem. Phys. 2011, 13, 19238-19255. [CrossRef] [PubMed]

5. Shiraiwa, M.; Li, Y.; Tsimpidi, A.; Karydis, V.; Berkemeier, T.; Pandis, S.N.; Lelieveld, J.; Koop, T.; Pöschl, U. Global distribution of particle phase state in atmospheric secondary organic aerosols. Nat. Commun. 2017, 8, 15002. [CrossRef]

6. Bateman, A.P.; Belassein, H.; Martin, S.T. Impactor Apparatus for the Study of Particle Rebound: Relative Humidity and Capillary Forces. Aerosol Sci. Technol. 2013, 48, 42-52. [CrossRef]

7. Renbaum-Wolff, L.; Grayson, J.W.; Bateman, A.P.; Kuwata, M.; Sellier, M.; Murray, B.; Shilling, J.; Martin, S.T.; Bertram, A.K. Viscosity of -pinene secondary organic material and implications for particle growth and reactivity. Proc. Natl. Acad. Sci. USA 2013, 110, 8014-8019. [CrossRef] [PubMed]

8. Zhang, Y.; Sanchez, M.S.; Douet, C.; Wang, Y.; Bateman, A.P.; Gong, Z.; Kuwata, M.; Renbaum-Wolff, L.; Sato, B.B.; Liu, P.F.; et al. Changing shapes and implied viscosities of suspended submicron particles. Atmos. Chem. Phys. Discuss. 2015, 15, 7819-7829. [CrossRef]

9. Power, R.M.; Simpson, S.H.; Reid, J.P.; Hudson, A.J. The transition from liquid to solid-like behaviour in ultrahigh viscosity aerosol particles. Chem. Sci. 2013, 4, 2597-2604. [CrossRef]

10. Maclean, A.M.; Smith, N.R.; Li, Y.; Huang, Y.; Hettiyadura, A.P.S.; Crescenzo, G.V.; Shiraiwa, M.; Laskin, A.; Nizkorodov, S.A.; Bertram, A.K. Humidity-Dependent Viscosity of Secondary Organic Aerosol from Ozonolysis of $\beta$-Caryophyllene: Measurements, Predictions, and Implications. ACS Earth Space Chem. 2021, 5, 305-318. [CrossRef]

11. Reid, J.P.; Bertram, A.K.; Topping, D.; Laskin, A.; Martin, S.T.; Petters, M.D.; Pope, F.D.; Rovelli, G. The viscosity of atmospherically relevant organic particles. Nat. Commun. 2018, 9, 1-14. [CrossRef] [PubMed]

12. Song, Y.C.; Haddrell, A.E.; Bzdek, B.R.; Reid, J.P.; Bannan, T.; Topping, D.O.; Percival, C.; Cai, C. Measurements and Predictions of Binary Component Aerosol Particle Viscosity. J. Phys. Chem. A 2016, 120, 8123-8137. [CrossRef] [PubMed]

13. Kiland, K.J.; MacLean, A.M.; Kamal, S.; Bertram, A.K. Diffusion of Organic Molecules as a Function of Temperature in a Sucrose Matrix (a Proxy for Secondary Organic Aerosol). J. Phys. Chem. Lett. 2019, 10, 5902-5908. [CrossRef] [PubMed]

14. Petters, S.S.; Kreidenweis, S.M.; Grieshop, A.P.; Ziemann, P.J.; Petters, M.D. Temperature- and Humidity-Dependent Phase States of Secondary Organic Aerosols. Geophys. Res. Lett. 2019, 46, 1005-1013. [CrossRef]

15. Chen, G.Y.; Warmack, R.J.; Thundat, T.; Allison, D.P.; Huang, A. Resonance response of scanning force microscopy cantilevers. Rev. Sci. Instrum. 1994, 65, 2532-2537. [CrossRef]

16. Van Eysden, C.A.; Sader, J. Frequency response of cantilever beams immersed in viscous fluids with applications to the atomic force microscope: Arbitrary mode order. J. Appl. Phys. 2007, 101, 44908. [CrossRef] 
17. Sader, J. Frequency response of cantilever beams immersed in viscous fluids with applications to the atomic force microscope. J. Appl. Phys. 1998, 84, 64-76. [CrossRef]

18. Ahmed, N.; Nino, D.F.; Moy, V.T. Measurement of solution viscosity by atomic force microscopy. Rev. Sci. Instrum. 2001, 72, 2731-2734. [CrossRef]

19. Boskovic, S.; Chon, J.; Mulvaney, P.; Sader, J. Rheological measurements using microcantilevers. J. Rheol. 2002, 46, 891. [CrossRef]

20. Song, C.; Zaveri, R.A.; Alexander, M.L.; Thornton, J.A.; Madronich, S.; Ortega, J.V.; Zelenyuk, A.; Yu, X.-Y.; Laskin, A.; Maughan, D.A. Effect of hydrophobic primary organic aerosols on secondary organic aerosol formation from ozonolysis of $\alpha$ pinene. Geophys. Res. Lett. 2007, 34, L20803. [CrossRef]

21. Wang, G.; Kawamura, K.; Lee, S.; Ho, K.; Cao, J. Molecular, Seasonal, and Spatial Distributions of Organic Aerosols from Fourteen Chinese Cities. Environ. Sci. Technol. 2006, 40, 4619-4625. [CrossRef]

22. Chenyakin, Y.; Ullmann, D.A.; Evoy, E.; Renbaum-Wolff, L.; Kamal, S.; Bertram, A.K. Diffusion coefficients of organic molecules in sucrose-water solutions and comparison with Stokes-Einstein predictions. Atmos. Chem. Phys. Discuss. 2017, 17, 2423-2435. [CrossRef]

23. Palchoudhury, S.; Baalousha, M.; Lead, J.R. Chapter 5-Methods for Measuring Concentration (Mass, Surface Area and Number) of Nanomaterials. In Frontiers of Nanoscience; Baalousha, M., Lead, J.R., Eds.; Elsevier: Amsterdam, The Netherlands, 2015; pp. 153-181.

24. Sader, J.E.; Chon, J.; Mulvaney, P. Calibration of rectangular atomic force microscope cantilevers. Rev. Sci. Instrum. 1999, 70, 3967-3969. [CrossRef]

25. Green, C.P.; Sader, J. Torsional frequency response of cantilever beams immersed in viscous fluids with applications to the atomic force microscope. J. Appl. Phys. 2002, 92, 6262-6274. [CrossRef]

26. Telis, V.; Telis-Romero, J.; Mazzotti, H.; Gabas, A. Viscosity of Aqueous Carbohydrate Solutions at Different Temperatures and Concentrations. Int. J. Food Prop. 2007, 10, 185-195. [CrossRef]

27. De Lorenzi, L.; Fermeglia, M.; Torriano, G. Density, Refractive Index, and Kinematic Viscosity of Diesters and Triesters. J. Chem. Eng. Data 1997, 42, 919-923. [CrossRef]

28. Galligan, J.; McKrell, T. Thermal activation and viscosity. Phys. B Condens. Matter. 2000, 291, 131-134. [CrossRef]

29. Ojovan, M.I. Viscosity and Glass Transition in Amorphous Oxides. Adv. Condens. Matter. Phys. 2008, 2008, 1-23. [CrossRef]

30. Messaâdi, A.; Dhouibi, N.; Hamda, H.; Belgacem, F.B.M.; Adbelkader, Y.H.; Ouerfelli, N.; Hamzaoui, A.H. A New Equation Relating the Viscosity Arrhenius Temperature and the Activation Energy for Some Newtonian Classical Solvents. J. Chem. 2015, 2015, 1-12. [CrossRef]

31. Lee, H.D.; Ray, K.K.; Tivanski, A.V. Solid, Semisolid, and Liquid Phase States of Individual Submicrometer Particles Directly Probed Using Atomic Force Microscopy. Anal. Chem. 2017, 89, 12720-12726. [CrossRef]

32. Lee, H.D.; Kaluarachchi, C.P.; Hasenecz, E.S.; Zhu, J.Z.; Popa, E.; Stone, E.A.; Tivanski, A.V. Effect of dry or wet substrate deposition on the organic volume fraction of core-shell aerosol particles. Atmos. Meas. Tech. 2019, 12, 2033-2042. [CrossRef]

33. Lee, H.D.; Morris, H.S.; Laskina, O.; Sultana, C.M.; Lee, C.; Jayarathne, T.; Cox, J.L.; Wang, X.; Hasenecz, E.S.; DeMott, P.J.; et al. Organic Enrichment, Physical Phase State, and Surface Tension Depression of Nascent Core-Shell Sea Spray Aerosols during Two Phytoplankton Blooms. ACS Earth Space Chem. 2020, 4, 650-660. [CrossRef]

34. Lee, H.D.; Tivanski, A.V. Atomic Force Microscopy: An Emerging Tool in Measuring the Phase State and Surface Tension of Individual Aerosol Particles. Annu. Rev. Phys. Chem. 2021, 72, 235-252. [CrossRef] [PubMed] 